\title{
Psychological and Social Factors That Influence Quality of Life: Gender, Age and Professional Status Differences
}

\author{
Gaspar, T. \\ Lusiada University, CLISSIS, Lisbon, Portugal \\ ISAMB/University of Lisbon, Lisbon, Portugal
}

\author{
Cabrita, T., Rebelo, A. \\ Lusiada University, CLISSIS, Lisbon, Portugal
}

Gaspar de Matos, M.

University of Lisbon, WJRC, Lisbon, Portugal

\begin{abstract}
Quality of life is influenced by psychological and social factors. Quality of life in the ageing process is a complex and multidimensional process, also influenced by gender, age and professional status. The data were collected on a national level. The sample was composed by 1,330 people, $62.2 \%$ of which were female with ages ranging between 55 and 75 years old. $34.4 \%$ of the sample mentioned having a chronic condition, $48.2 \%$ of which had diabetes. Three regression models were created in order to understand the quality of life in ageing population in a biopsychosocial perspective. Results showed that quality of life in ageing population is influenced by psychological factors (purpose of life and stress management skills) and by social factors (family and friends social support). Gender, age, and professional status can also influence quality of life. Our study allowed us to conclude that quality of life is influenced by physical, psychological, and social health. The psychological factors presented a more systematic and strong influence in quality of life on the ageing population.
\end{abstract}

Keywords: psychosocial factors, purpose of life, stress management, quality of life, social support, professional status

\section{Introduction}

The ageing process is inevitable for every human being since it's from the beginning of our birth that our body and mind initiates this process that will last until our death. The process of aging is not to be seen in a pejorative way since it's a natural event that resides in all living beings where changes occur in a multitude of factors of physical/biological, psychological, and social order. But aging is not equal for all, because our way of life is influenced by several factors: physiological, psychological, social, economic, environmental, and cultural (Tavares, Bolina, Dias, Ferreira, \& Haas, 2014). In the beginning of the $21^{\text {st }}$ century, Europe was the continent with the longest lifespan of 80 years, while Africa had the lowest at 58 years (Roser, 2015). This process of expanding humanity life has been in process for a millennia. With the purpose of improving our own QOL

\footnotetext{
*Acknowledgements: This work was supported by Minerva Foundation, Lisbon, Portugal.

Gaspar, T., Ph.D., professor, Psychology Department, Lusiada University; University of Lisbon.

Cabrita, T., Ph.D., professor, Psychology Department, Lusiada University.

Rebelo, A., Ph.D., professor, Psychology Department, Lusiada University.

Gaspar de Matos, M., Ph.D., professor, FMH, University of Lisbon.
} 
(Quality of Life) since the beginning of civilization we have been increasing our own life by building villages, towns, cities, and countries. Our basic needs, such as food, shelter, and security could be easily fulfilled giving more opportunities to research other "life-extending" areas like medicine.

Over the last century, infectious diseases have been replaced by chronic health problems as the dominant health care burden (Avolio, Montagnoli, Marino, Basso, Furia, Ricciardi, \& Belvis, 2013). Most of those problems are related to aging. Even though humanity has prolonged their lives the price we paid was not small because even though we live more we also live with diseases that can affect our QOL. A greater longevity does not correspond to a better QOL since this concept goes beyond morbidity and mortality (Khan \& Tahir, 2014). The QOL involves the perception of well-being in several areas of the person's life, mainly the physical, psychological, social, and environmental. In recent years, there has been a growing interest in the concept of QOL. This is also associated with a paradigm shift in which the bio-medical model is replaced by the biopsychosocial model. Health and disease began to be seen as being interconnected, instead of being seen as disconnected. Associated with this change there is also interest in improvement of QOL. The QOL in old age can be conceptualized by two main approaches: the subjective evaluation of a person's overall QOL and the objective evaluation of a person's QOL.

The concept of QOL is multidimensional and complex which encompasses several criteria, such as family, emotional and physical well-being, physiological function, capacity to maintain daily activities, and other subjective components, such as the satisfaction of life, where a person observes their expectations and the achievement of objectives. This concept can be seen at the level of satisfaction of the person in the areas of family, love, emotional, social, environmental, and existential, as well as the level of functional capacity, intellectual activity, socio-economic level, satisfaction with the job, and the environment that they live in (Oliveira, Oliveira, Arantes, \& Alencar, 2010; Torres, Reis, Reis, \& Fernandes, 2009). A study carried by Netuveli, Wiggins, Hildon, Montgomery, and Blane (2006) showed that there wasn't a single determinant factor that affected the QOL in old age. Although there were several factors that could affect it. Some of those factors that can affect negatively the QOL, such as poor financial situation, depression, functional limitation resulted of longstanding illness or incapacity, and limitations in everyday activities. On the other hand, taking residence in an appreciated neighborhood, having trusting relationships with children, family, and friends and a good financial situation can improve the QOL. The evidence in this study also showed that the QOL could improve during early old age followed by a healthy aging. A healthy aging can be seen as a process of using every opportunity to improve and preserve the QOL; the physical, social, and mental wellness; and capabilities, as well as the individual independence and autonomy (Han, Lee, Gu, Oh, Han, \& Kim, 2015).

\section{Retirement}

Even though there are several studies that show both the advantages and disadvantages of retirement, as well as the implications (in physical, mental, and social levels), the reality in nowadays is that, much thanks to the economic condition of certain countries, the elderly are likely to keep working after they retire since the pension they received is not enough to cover all their living expenses.

The process of retirement is a big change in the elderly life both at a psychological and social level since these alterations may represent a social devaluation and the loss of a professional identity (Alvarenga, Kiyan, Bitencourt, \& Wanderley, 2009). 
Most humans achieve a kind of purpose through their work and when this activity comes to an end and they retire, there are several reactions to it. Like any change in a person's life, it can be frightening, trigger anxiety or any other menaces to the psychological well-being. The retirement is like a confrontation with the spare time that they have. Time used to put into work is now vacant and there's a lack of knowledge of what to do with it. In these times, feelings of emptiness, lack of purpose, depression, anxiety, irritability, withdraw or losing relations with the colleagues, the feelings of achievement their work provided, plus adapting to a new reality of spending more time with family can become a psychological wound that weights on the person resulting in a reduction in QOL (Alvarenga et al., 2009). Sometimes these feelings and issues emerge before the retirement, the forethought of these can cause severe psychological harm to oneself and other problems to the dynamic of their families and close ones. Thus, it is important to bet on prevention by helping the elderly planning and realizing that there are options after retirement, which their work routine isn't all they had and that from now on they will work on constructing a good retirement and improve their QOL. Elderly people can still feel useful by finding a new objective and a new purpose.

According to Wang and Shultz (2010), retirement is not a single, onetime event but rather a psychological process that unfolds over a period of time that will vary depending on the circumstances of each individual.

The present study aims to a deeper understanding about the impact of psychosocial factors in quality of life on ageing population and to identify related gender, age, and professional status (active professional and retirement) differences.

\section{Method}

\section{Participants}

The sample consisted of 1,330 participants with ages between 55 and 75 years old, whose average age was about 60 years. Regarding gender, $62 \%$ were female and $38 \%$ were male, and $34.4 \%$ of the sample mentioned having a chronic condition. In the participants, $47 \%$ maintained an occupation and $46 \%$ were retired.

\section{Instruments}

The instrument was composed by some sociodemographic related questions and by questionnaires related to quality of life, social support, purpose of life, and psychosocial factors at work.

Quality of life-WHOQOL-BREF (World Health Organization Quality of Life-Brief). The name of the instrument is WHOQOL-BREF the authors and date of the original version is the WHOQOL Group (1994) and in this study it was used the portuguese version (Canavarro et al., 2007). It is a generic, multidimensional, and multicultural measure to assess subjective quality of life and can be used in a wide range of psychological and physical disorders, as well as in healthy individuals. It consists of 26 items and includes four domains of quality of life: physical, psychological, social affairs, and environment. Each of these domains consists in facets of quality of life that summarize the particular domain of quality of life to which they belong. This measure also allows the calculation of a global indicator in particular facet of the overall quality of life.

Items are assessed on a Likert scale of five points in which a higher value represents a better perception of quality of life.

Internal consistency measured by Cronbach's alpha shows acceptable values whether analysing the four domains $(\alpha=0.90)$ or each individual domain ranging from Spirituality $(\alpha=0.86)$ to Psychological $(\alpha=0.95)$.

Psychosocial factors of work-COPSOQ (Copenhagen Psychosocial Questionnaire). The instrument that measured psychosocial factors at work (COPSOQ II) was developed and validated by Kristensen, Hannerz, 
Hogh, and Vilhelm (2005) in collaboration with the Danish National Institute of Occupational Health in Copenhagen. The main objective is to evaluate the psychosocial factors at work. The internal consistency (Cronbach's alpha) subscales of COPSOQ is between 0.60 and 0.90 (with the exception of two subscales).

The COPSOQ II follows a multidimensional concept and is intended to cover the general needs involved in the scope of the concept of "stress at work". It is based on demand model and control trying to explain the psychosocial risk factors at work as a result of high job demands and low social support. The short version includes the psychosocial dimensions with epidemiological evidence related to health. All versions evaluate exposure indicators (psychosocial risks) and indicators of its effect (health, satisfaction and stress). Items are assessed on a Likert scale of five points: (1) Never/hardly ever; (2) Rarely; (3) Sometimes; (4) Often; and (5) Always, or (1) Nothing/almost nothing; (2) Alittle; (3) Moderately; (4) Very; and (5) Extremely.

Satisfaction scale with social support-Ribeiro-ESSS (Escala de Satisfação com o Suporte Social Social Support Satisfaction Scale). The instrument name is ESSS and was developed and validated by Ribeiro (1999). The ESSS was built to measure satisfaction with the existing social support. The internal consistency (Cronbach's alpha) of the total scale is 0.85 . This instrument consists of 15 sentences of self-completion as a set of statements. The subject indicates the degree to which you agree/disagree with the statement in a Likert scale with five positions: "strongly agree", "agree mostly", "neither agree nor disagree", "disagree mostly", and "strongly disagree".

The ESSS can extract four dimensions or factors: satisfaction with friends/acquaintances (SA), intimacy (IN), satisfaction with family (SF), and social activities (AS). The scale also allows to obtain a global score (ESSS) representing the highest marks to a perception of greater satisfaction with social support.

PIL (Purpose in life)-PartA, or PIL-Test (Purpose in LifeTest). The instrument related to life goals (PIL) was developed and validated by Crumbaugh and Maholick (1964) and reviewed by Harlow, Newcomb, and Bentler (1987), constituting the PIL-R (Purpose in Life Test) version. The instrument assess the construct sense of life in their ranks: the degree of existential emptiness and the level of achievement of meaning in life. The internal consistency (Cronbach's alpha) of the test is 0.88 for Portuguese population of advanced adulthood. This instrument consists of a Likert scale composed by 20 items which aims to fundamentally assess the level of existential emptiness and the sense of willing to live in an evaluation of a seven point scale: (1) Strongly disagree; (2) Disagree largely; (3) Somewhat disagree; (4)Neither agree nor disagree; (5) Somewhat agree; (6) Agree for the most part; and (7) Totally agree. The items in this scale include the following aspects: purpose in life, satisfaction with life, freedom, fear of death, suicidal ideation, and life's worth.

\section{Procedure}

Initially the Psychosocial Factors of Work (COPSOQ) (Kristensen et al., 2005) suffered a process of translation and back translation involving two Portuguese researchers and a bilingual researcher (Portuguese/English).

All demographic issues and assessment tools had been integrated in the form of a battery. This battery was tested in a group of 20 people between 55 and 75 years old with different socio-economic and cultural characteristics in order to assess suitability.

The final version included some changes in demographics, in order to presentation of the instruments and the scale of violence in the work was removed from the work Psychosocial Factors Scale (COPSOQ) (Kristensen et al., 2005). 
Several organizations were contacted, such as unions, businesses, municipalities, day care centres, senior universities, NGOs working with people within the age range of the study, and others to collaborate on data collection. Data collection was carried out with the institutions that agreed to cooperate and with people who agreed to complete the questionnaire. The questionnaire was self-completion anonymous and confidential.

\section{Results}

Related to global perception of Quality of Life, $4.0 \%$ of the participants referred that it was bad or very bad, $31.1 \%$ said that it was either bad or good, and $64.9 \%$ said that it was good or very good. In relation to satisfaction with their health, $10.6 \%$ of the participants referred that it was unsatisfied or vey unsatisfied, $21.1 \%$ was either satisfied or unsatisfied, and $68.3 \%$ was satisfied or very satisfied with their health.

In relation with quality of life and quality of life dimensions, items are assessed on a Likert scale of five points in which higher value represents a better perception of quality of life. The participants presented a good quality of life in different dimensions. The participants were less satisfied with the dimension related to environment.

Table 1

WHOQOL Dimensions Means and DP

\begin{tabular}{lll}
\hline Dimensions & Mean & SD \\
\hline Quality of life global & 3.69 & 0.69 \\
Quality of life physical & 3.88 & 0.68 \\
Quality of life psychological & 3.90 & 0.60 \\
Quality of life social & 3.85 & 0.62 \\
Quality of life environmental & 3.48 & 0.59 \\
\hline
\end{tabular}

Statistical differences were found between male and female. Female participants presented less healthy indicators than the male participants. Female participants presented low values in dimensions related to physical, psychological, and environmental quality of life.

Table 2

ANOVA-Quality of Life Dimensions and Gender Differences

\begin{tabular}{llllll}
\hline \multirow{2}{*}{ Dimensions } & \multicolumn{3}{c}{ Female } & \multicolumn{3}{c}{ Male } & \multirow{2}{*}{$F$} \\
\cline { 2 - 5 } & $M$ & $S D$ & $M$ & $S D$ & $($ n.s. $)$ \\
Quality of life global & 3.65 & 0.71 & 3.71 & 0.67 & $13.02^{* * *}$ \\
Quality of life physical & 3.83 & 0.70 & 3.98 & 0.64 & $16.83^{* * *}$ \\
Quality of life psychological & 3.85 & 0.61 & 3.99 & 0.57 & $($ n.s. $)$ \\
Quality of life social & 3.85 & 0.63 & 3.84 & 0.63 & $5.24^{*}$ \\
Quality of life environmental & 3.45 & 0.59 & 3.54 & 0.59 & \\
\hline
\end{tabular}

Notes. ${ }^{*} \mathrm{p}<0.05 ;{ }^{* * *} \mathrm{p}<0.001$.

Statistical differences were found between age groups. Participants with 61 years old or more presented less healthy indicators than the younger participants. Older participants presented low values in all quality of life dimensions except environmental quality of life. 
Table 3

ANOVA-Quality of Life Dimensions and Age Differences

\begin{tabular}{|c|c|c|c|c|c|}
\hline \multirow{2}{*}{ Dimensions } & \multicolumn{2}{|c|}{ Until 60 years old } & \multicolumn{2}{|c|}{61 years old or more } & \multirow{2}{*}{$F$} \\
\hline & $M$ & $S D$ & $M$ & $S D$ & \\
\hline Quality of life global & 3.73 & 0.67 & 3.62 & 0.70 & $7.37^{* *}$ \\
\hline Quality of life physical & 3.95 & 0.67 & 3.82 & 0.69 & $10.34^{* * *}$ \\
\hline Quality of life psychological & 3.94 & 0.59 & 3.87 & 0.60 & $3.83^{*}$ \\
\hline Quality of life social & 3.90 & 0.63 & 3.81 & 0.61 & $6.16^{* *}$ \\
\hline Quality of life environmental & 3.47 & 0.60 & 3.49 & 0.59 & (n.s.) \\
\hline
\end{tabular}

Notes. ${ }^{*} \mathrm{p}<0.05 ;{ }^{* *} \mathrm{p}<0.01 ;{ }^{* * *} \mathrm{p}<0.001$.

Statistical differences were found between professional status groups. Retired participants presented less quality of life indicators than the other participants. Retired participants presented low values in all quality of life dimensions except environmental quality of life. Professionally active participants presented lower values in environmental quality of life dimension.

Retired and professionally active participants presented higher values in all quality of life dimensions except social quality of life. Professionally active participants presented higher values in social quality of life dimension.

Table 4

ANOVA-Quality of Life Dimensions and Professional Status Differences

\begin{tabular}{llllllll}
\hline & \multicolumn{2}{c}{ Professionally active } & & Retired & \multicolumn{2}{c}{$\begin{array}{c}\text { Retired and } \\
\text { professionally active }\end{array}$} \\
\hline Dimensions & $M$ & $S D$ & $M$ & $S D$ & $M$ & $S D$ & \\
Quality of life global & 3.73 & 0.67 & 3.58 & 0.71 & 3.85 & 0.62 & $9.83^{* * *}$ \\
Quality of life physical & 3.95 & 0.65 & 3.76 & 0.70 & 4.24 & 0.63 & $21.30^{* * *}$ \\
Quality of life psychological & 3.92 & 0.58 & 3.85 & 0.61 & 4.16 & 0.54 & $9.00^{* * *}$ \\
Quality of life social & 3.93 & 0.61 & 3.78 & 0.63 & 3.86 & 0.60 & $8.64^{* * *}$ \\
Quality of life environmental & 3.46 & 0.59 & 3.49 & 0.57 & 3.69 & 0.67 & $5.11^{* *}$ \\
\hline
\end{tabular}

Notes. ${ }^{* *} \mathrm{p}<0.01 ;{ }^{* * *} \mathrm{p}<0.001$.

Three progressive models were built with quality of life as dependent variable. The first model with sociodemographic variables (age and gender), the second model to which was introduced social variables (friends and family social support), and the third integrative model that included sociodemographic, social, and psychological variables (stress management and purpose of life).

The model 1 with demographic variables, regarding the Regression Model 1 in table 5, achieved a not very strong model [Z (5.32) 2.918; $\mathrm{p}<0.005]$ and the explained variance (Adjusted R squared) was $1 \%$.

A similar model (Model 2) was built using the demographic variables and the social variables and achieved a more robust model. Regarding the Regression Model in table 5, an adequate model was achieved [Z (45.69) 3.917; $\mathrm{p}<0.001$ ] and the explained variance (Adjusted R squared) was 13\%.

The third model was built using demographic, psychological, and social variables and achieved a robust model. Regarding the Regression Model in table 5, an adequate model was achieved [Z (90.12) 5.915; p < 0.001 ] and the explained variance (Adjusted R squared) was 33\%. 
Table 5

Impact of Demographic, Psychological and Social Characteristics in Quality of Life in Ageing PeopleRegression Models-Dependent Variable Quality of Life

\begin{tabular}{|c|c|c|c|c|}
\hline & $\begin{array}{l}\text { Unstandardized } \\
\text { coefficients }\end{array}$ & $\begin{array}{l}\text { Standardized } \\
\text { coefficients }\end{array}$ & & \\
\hline & $B$ & Std. Error & Beta & $t$ \\
\hline \multicolumn{5}{|l|}{ Model 1} \\
\hline Constant & 4.10 & 0.19 & & \\
\hline Age & -0.01 & 0.01 & -0.10 & $-2.95^{* * *}$ \\
\hline Gender & 0.08 & 0.05 & 0.06 & n.s. \\
\hline \multicolumn{5}{|l|}{ Model 2} \\
\hline Constant & 2.71 & 0.21 & & \\
\hline Age & -0.01 & 0.01 & -0.10 & $-3.28^{* * *}$ \\
\hline Gender & 0.07 & 0.04 & 0.05 & n.s. \\
\hline Social support & .041 & 0.04 & 0.34 & $11.18^{* * *}$ \\
\hline \multicolumn{5}{|l|}{ Model 3} \\
\hline Constant & 1.453 & 0.220 & & \\
\hline Age & -0.006 & 0.002 & -0.063 & $-2.240^{*}$ \\
\hline Gender & -0.028 & 0.038 & -0.020 & n.s. \\
\hline Social support & 0.063 & 0.039 & 0.053 & n.s. \\
\hline Purpose of life & 0.258 & 0.032 & 0.279 & $8.184^{* * *}$ \\
\hline Stress management at work & 0.333 & 0.030 & 0.353 & $11.11^{* * *}$ \\
\hline
\end{tabular}

\section{Discussion}

Our results show that quality of life is influenced by gender, age, and professional situation, as well as psychological and social factors. And health conditions should be understood in a biopsychosocial perspective. This perspective includes the biological aspects that can affect the patient's biological functioning including the psychological system related to emotions and personal. It also includes the social system associated to cultural, environmental, and family/friends influences on the expression and experience of illness. This model shows that health has being determinated and influenced by biological, psychological, and social factors, and also shows that illness is a consequence of the interplay of these factors (Schneider, Gruman, \& Coutts, 2005; Taylor, 2012).

Most of the participants reported that they had a good quality of life. Naing, Nanthamongkolchai, and Munsawaengsub (2010) obtained similar results in their study. On this perspective, social support satisfaction with family and friends is related to quality of life and psychological factors, such as purpose of life and stress management skills are also related to quality of life in ageing population (Brown et al., 2010; Crouchley \& Daly, 2007; Gaspar \& Torres, 2015; Taichman et al., 2005). Age and gender presented relevant influence in quality of life. In general, female and older participants presented less healthy indicators than the male and younger participants. Those results are similar to the studies developed by Gholami et al. (2013).

Referring to the professional situation, our results reflect that retired participants with some professional activity present higher healthy indicators than the active professionals and retired participants. The study developed by Alvarenga et al., (2009) supports those results. The process of retirement brings psychological 
and social changes and challenges, these alterations may represent a social devaluation and the loss of a professional identity.

The model to understand the factors that influence quality of life that includes age, gender, professional situation, social support, and psychological variables shows to be the most robust model. The psychological variables (purpose of life and stress management) present the strongest impact in quality of life (Gaspar et al., 2012; Gaspar, Matos, Ribeiro, Leal, \& Ferreira, 2009; Lin et al., 2004). Psychological intervention can be integrated into usual care routine to assist people to make the recommended lifestyle changes. Including psychological factors in interventions is effective in the prevention and treatment of lifestyle-related diseases (Clark \& Hampson, 2001; SAMHSA Advisory, 2013).

The resultant models reported in table 5 presented a biopsychosocial perspective and showed robust results to ageing population. It also showed to be a good model to understand quality of life in ageing population (Brown et al., 2010; Crouchley \& Daly, 2007; Miranzi, Ferreira, Iwamoto, Pereira, \& Miranzi, 2008; Odili, Ugboka, \& Oparah, 2008; Taichman et al., 2005; Walker, 2005).

The achieved models showed that social and psychological characteristics presented a stronger explicative value on the ageing population quality of life. Therefore, we conclude that especially psychological and social factors can be considered protective factors related to ageing population. The prevention and intervention with ageing population should include the promotion of social and psychological skills in the target population, family, and community.

Promoting good health and healthy behaviours at all ages contributes to prevent or delay the development of chronic disease or other ageing related diseases. If the disease already exits it's important to minimize the consequences through early detection, quality care, and psychosocial skills promotion. Health promotion intervention in ageing population should create physical and social environments that foster health and the participation of older people and it is important to change personal and social attitudes in order to encourage the participation of older people (World Health Organization, 2012).

Monitoring quality of life in ageing population is particularly important, despite the variety of medical, social, and psychosocial interventions that they may have had. A psychologist, other social or health professionals who measure the quality of life can promote a better multidimensional welfare in ageing population in terms of family, community, and other areas that reflect risk or protective factors in relation to their ageing process.

The assessment of quality of life may be useful in screening and identifying individuals who are at risk of developing behaviour or health complications which is crucial for social programs, health promotion and prevention programs.

The relationship between quality of life, age, gender, professional status, psychological factors, and social factors and the protective impact that personal and social factors can have in ageing population health are important indicators. They provide a strong argument for scientific research in quality of life in ageing population using a biopsychosocial perspective by psychologists, other social/health professionals, and community contexts who have to confront the challenge of providing services that are sensitive to cultural and individual differences (Huebner, Suldo, Smith, \& McKnight, 2004; World Health Organization, 2012).

The study presented some limitations. One of them was the representativeness as the participants were Portuguese and a convenience sample was used. So the results cannot be representative for ageing population. It could be interesting to study specific chronic diseases and comorbidity among diseases including mental health problems related to dementia, depression, and anxiety. 
Despite the study limitations, our conclusions and proposed models can be considered contributions to a better understanding and to promote a more effective intervention related to quality of live in ageing population using a biopsychosocial approach as well as a reinforce the relevance of psychological factors.

\section{Practical Implications}

Our results strongly suggest that being female with more than 60 years old and being retired without professional activity in ageing population can impair their quality of live or at least increase their vulnerability, but the most important feature is that this situation is really impacted by the strength of personal and social factors that can have a buffering effect. The intervention consequences of this impact are huge and call for a change in the organization of support services both in health and social services, for ageing people that must include a positive focus: the promotion of personal and social competences and the promotion of a social support network including family and community.

Having chronic health conditions can be considered a risk factor related to quality of live in ageing population. The impact of this risk or the health complications and psychological consequences can be reduced if ageing people develop social and psychological skills to face the risk and improve positive ageing opportunities.

\section{References}

Alvarenga, L., Kiyan, L., Bitencourt, B., \& Wanderley, K. (2009). Las repercusiones de la jubilaciónen la calidad de vida del anciano [The impact of retirement on the quality of life of the elderly]. Revista da Escola de Enfermagem da USP [Journalofnursingschool USP], 43(4), 796-802. doi: 10.1590/S0080-62342009000400009

Avolio, M., Montagnoli, S., Marino, M., Basso, D., Furia, G., Ricciardi, W., \& Belvis, A. (2013). Factors influencing quality of life for disabled and nondisabled elderly population: The results of a multiple correspondence analysis. Current Gerontology and Geriatrics Research. Retrieved from http://dx.doi.org/10.1155/2013/258274

Brown, D., Pleasants, R., Ohar, J., Kraft, M., Donohue, J., Mannino,D., ... Herrick, H. (2010). Health-related quality of life and chronic obstructive pulmonary disease in North Carolina. North American Journal of Medical Sciences, 2(2), 60-65.

Canavarro, M. C., Simões, M. R., Vaz Serra, A., Pereira, M., Rijo, D., Quartilho, M. J., \& Carona, C. (2007). Instrumento de avaliação da qualidade de vida da Organização Mundial de Saúde: WHOQOL-Bref [Quality of life Assessment Instrument of the World Health Organization]. In M. R. Simões, C. Machado, M. Gonçalves, \& L. Almeida (Eds.), Avaliação psicológica. Instrumentos validados para a população Portuguesa [Psychological evaluation. Instruments validated for the Portuguese population] (Vol. III, pp. 77-100). Coimbra: Quarteto Editora.

Clark, M., \& Hampson, S. E. (2001). Implementing a psychological intervention to improve lifestyle self-management in type 2 diabetes. Patient Education and Counseling, 42, 247-256.

Crouchley, K., \& Daly, A. (2007). Chronic disease and quality of life in Western Australia. Western Australia: Department of Health.

Crumbaugh, J. C., \& Maholick, L. T. (1964). An experimental study in existentialism: The psychometric approach to Frankl's concept of noogenic neurosis. Journal of Clinical Psychology, 20, 200-207.

Gaspar, T., \& Torres, I. (Coords.) (2015). Fatores psicossociais e profissionais promotores de qualidade de vida no processo de reforma e envelhecimento ativo [Psychosocial factors and professional quality of life promoters in retirement process and active ageing]. Retrieved from http://actas.lis.ulusiada.pt/index.php/envelhecimento

Gaspar, T., Matos, M. G., Ribeiro, J. L., Leal, I., Erhart, M., \& Ravens-Sieberer, U. (2012). Health-related quality of life in children and adolescents: Subjective well being. Spanish Journal of Psychology, 15(1), 177-186. Retrieved from http://dx.doi.org/10.5209/rev_SJOP.2012.v15.n1.37306

Gaspar, T., Matos, M. G., Ribeiro, J., Leal, I., \& Ferreira, A. (2009). Health-related quality of life in children and adolescents and associated factors. Journal of Cognitive and Behavioral Psychotherapies, 9(1), 33-48.

Gholami, A., Azini, M., Borji, A., Shirazi, F., Sharafi, Z., \& Zarei, E. (2013). Quality of life in patiets with type 2 diabetes: Application of WHOQOL-BREF scale. Shiraz E-Medical Journal, 14(3),162-171.

Han, K., Lee, Y., Gu, J., Oh, H., Han, J., \& Kim, K. (2015). Psychosocial factors for influencing healthy aging in adults in Korea. Health and Quality of Life Outcomes, 13:31. doi: 10.1186/s12955-015-0225-5 
Harlow, L., Newcomb, M., \& Bentler, P. (1987). Purpose in Life Test assessment using latent variable methods. British Journal of Clinical Psychology, 26, 235-236.

Huebner, E., Suldo, S., Smith, L., \& McKnight, C. (2004). Life satisfaction in children and youth: Empirical foundations and implications for school psychologists. Psychology in the Schools, 41(1), 81-93.

Khan, A., \& Tahir, I. (2014). Influence of social factors to the quality of life of the elderly in Malaysia. Open Medicine Journal, 1 , 29-35. doi: 10.2174/1874220301401010029

Kristensen, T. S., Hannerz, H., Hogh, A., \& Vilhelm, B. (2005). The Copenhegen psychosocial questionnaire-a tool for the assessment and improvement of the psychosocial work. Scand J Work Environ Health, 38, 438-449.

Lin, E. J., Katon, W., Von Korff, M., Rutter, C., Simon, G. E., Oliver, M., .. Young, B. (2004). Relationship of depression and diabetes self-care, medication adherence, and preventive care. Diabetes Care, 27(9), 2154-60.

Miranzi, S., Ferreira, F., Iwamoto, H., Pereira, G., \& Miranzi, M. (2008). Qualidade de vida de indivíduos com diabetes mellitus e hipertensão acompanhados por uma equipe de saúde da família [Quality of life of individuals with diabetes mellitus and hypertension accompanied by a family health team]. Texto contexto-Enferm, Florianópolis [Nursing context Florianópolis], 17(4), 672-679.

Naing, M., Nanthamongkolchai, S., \& Munsawaengsub, C. (2010). Quality of life of the elderly people in einme township irrawaddy division, Myanmar. Asia Journal Public Health, 1(2), 4-10.

Netuveli, G., Wiggins, R., Hildon, Z., Montgomery, S., \& Blane, D. (2006). Quality of life at older ages: Evidence from the English longitudinal study of aging (wave 1). Journal of Epidemiology \& Community Health, 60(4), 357-363. doi: 10.1136/jech.2005.040071

Odili, V., Ugboka, L., \& Oparah, A. (2008). Quality of life of people with diabetes in Benin city as measured with WHOQOL-BREF. The Internet Journal of Law, Healthcare and Ethics, 6(2). Retrieved from https://ispub.com/IJLHE/6/2/3421

Oliveira, A., Oliveira, N., Arantes, P., \& Alencar, M. (2010). Qualidade de vida em idosos que praticam atividade física: Uma revisão sistemática [Quality of life in the elderly who practice physical activity: A systematic review]. Revista Brasileira de Geriatria e Gerontologia [Brazilian Journal of Geriatrics and Gerontology], 13(2), 301-312.

Ribeiro, J. L. P. (1999). Escala de Satisfação com o Suporte Social [Social Support Satisfation Scale] (ESSS). Análise Psicológica [Psychological Analyse], 3(17), 547-558.

Roser, M. (2015). Life expectancy. $\quad$ Retrieved from http://ourworldindata.org/data/population-growth-vital-statistics/life-expectancy/

SAMHSA Advisory. (2013). Diabetes care for clients in behavioral health treatment. Fall, 12(1), 1-11.

Schneider, W., Gruman, J., \& Coutts, L. (2005). Applied social psychology: Understanding and addressing social and practical problems. Thousand Oaks, CA: Sage.

Taichman, D., Shin, J., Hud, L., Archer-Chicko, C., Kaplan, S., Sager, J. ... Palevsky, H. (2005). Health-related quality of life in patients with pulmonary arterial hypertension. Respiratory Research, 6(1). doi: 10.1186/1465-9921-6-92

Tavares, S., Bolina, F., Dias, A., Ferreira, S., \& Haas, J. (2014). Quality of life of elderly. Comparison between urban and rural areas. Investigación y Educaciónen Enfermería [Research and Education Nursing], 32(3), 401-413. doi: 10.1590/S0120-53072014000300005

Taylor, S. E. (2012). Health Psychology (8th ed.). New York, NY: McGraw HIll.

The WHOQOL Group. (1994). Development of the WHOQOL: Rationale and current status. International Journal of Mental Health, 23(3), 24-56.

Torres, G., Reis, L., Reis, L., \& Fernandes, M. (2009). Quality of life and associated factors in functionally dependent elderly in the hinterland of Northeast Brazil. Jornal Brasileiro de Psiquiatria [Brazilian Journal of Psychiatry], 58(1), 39-44. Retrieved from http://dx.doi.org/10.1590/S0047-20852009000100006

Walker, A. (2005). A European perspective on quality of life in old age. European Journal of Ageing, 2 (1), 2-12.

Wang, M., \& Shultz, K. (2010). Employee retirement: A review and recommendations for future investigation. Journal of Management, 36(1), 172-206. doi: 10.1177/0149206309347957

World Health Organization. (2012). Good health adds life to years: Global brief world health 2012. Geneve: Switzerland. 